\title{
Prohibitin: a prime candidate for a pleiotropic effector that mediates sex differences in obesity, insulin resistance, and metabolic dysregulation
}

\author{
Yang Xin Zi Xu', Geetika Bassi ${ }^{1}$ and Suresh Mishra ${ }^{1,2^{*}}$ (I)
}

\begin{abstract}
Adipocytes and macrophages, the two major constituents of adipose tissue, exhibit sex differences and work in synergy in adipose tissue physiology and pathophysiology, including obesity-linked insulin resistance and metabolic dysregulation. Sex steroid hormones play a major role in sex differences in adipose tissue biology. However, our knowledge of the molecules that mediate these effects in adipose tissue remains limited. Consequently, it remains unclear whether these effector molecules in different adipose and immune cell types are distinct or if there are also pleiotropic effectors. Recently, a protein named prohibitin (PHB) with cell compartment- and tissue-specific functions has been found to play a role in sex differences in adipose and immune functions. Transgenic (Tg) mouse models overexpressing PHB (PHB-Tg) and a phospho-mutant PHB (mPHB-Tg) from the fatty acid binding protein-4 (Fabp-4) gene promoter display sex-neutral obesity; however, obesity-related insulin resistance and metabolic dysregulation are male-specific. Intriguingly, with aging, the male PHB-Tg mice developed hepatic steatosis and subsequently liver tumors whereas the male mPHB-Tg mice developed lymph node tumors and splenomegaly. Unlike the male transgenic mice, the female PHB-Tg and mPHB-Tg mice remain protected from obesity-related metabolic dysregulation and tumor development. In conclusion, the sex-dimorphic metabolic and immune phenotypes of PHB-Tg and mPHB-Tg mice have revealed PHB as a pleiotropic effector of sex differences in adipose and immune functions. In this mini-review, we will discuss the pleiotropic attributes of PHB and potential mechanisms that may have contributed to the sex-dimorphic metabolic phenotypes in PHB-Tg and mPHB-Tg mice, which warrant future research. We propose that PHB is a prime candidate for a pleiotropic mediator of sex differences in adipose and immune functions in both physiology and pathophysiology, including obesity, insulin resistance, and metabolic dysregulation.
\end{abstract}

Keywords: Mitochondria, Sex steroids, O-GlcNAc transferase, Estrogen receptors, Androgen receptors, Transgenic mice

\section{Background}

Obesity (and its associated metabolic abnormalities) is an increasingly common ailment worldwide. It is a risk factor for a variety of diseases, including metabolic syndrome, type 2 diabetes, cardiovascular disease, and some types of cancer [1-3], which are also growing in parallel

\footnotetext{
* Correspondence: suresh.mishra@umanitoba.ca

'Department of Physiology and Pathophysiology, College of Medicine, Rady Faculty of Health Sciences, University of Manitoba, Rm. 843 JBRC/715 McDermot Avenue, Winnipeg, MB R3E 3P4, Canada

${ }^{2}$ Department of Internal Medicine, College of Medicine, Rady Faculty of Health Sciences, University of Manitoba, Winnipeg, Canada
}

with obesity. As the magnitude of obesity-related health problems is enormous, it has been an extensively investigated area of biomedical research for the last four decades. Accumulating evidence over the years has provided substantial proof that adipose tissue-specific immune dysregulation in the form of low-grade inflammation is an integral component of obesity-related metabolic abnormalities [4-6]. Notably, adipose and immune functions display sex differences in physiology and pathophysiology, including adipose tissue distribution and functions, obesity, insulin resistance, and metabolic syndrome [7-10]. In spite of extensive research on adipose tissue biology pertinent to

(c) The Author(s). 2019 Open Access This article is distributed under the terms of the Creative Commons Attribution 4.0 International License (http://creativecommons.org/licenses/by/4.0/), which permits unrestricted use, distribution, and reproduction in any medium, provided you give appropriate credit to the original author(s) and the source, provide a link to the Creative Commons license, and indicate if changes were made. The Creative Commons Public Domain Dedication waiver (http://creativecommons.org/publicdomain/zero/1.0/) applies to the data made available in this article, unless otherwise stated. 
obesity, a number of fundamental questions remain unanswered, especially in the context of sex differences in adipose tissue biology and pathobiology. There are a number of potential factors that may contribute to sex differences in adipose tissue functions in health and disease, including sex chromosomes, sex hormones, mitochondria, and epigenetic factors [11]. However, our knowledge of effector molecules that mediate sex differences in adipose and immune functions remains poor. It is also unclear whether these effector molecules in different adipose and immune cell types are distinct, or if there are common effector molecules, and whether the sex differences in adipose and immune functions influence each other.

Prohibitin (PHB) is an evolutionarily conserved pleiotropic protein, which localizes to different cellular compartments, including the nucleus, mitochondria, and cell membrane. It has cell compartment and cell/tissue-specific functions (reviewed in $[12,13])$. For example, PHB has a role in adipocyte differentiation and in cell signaling in various cell types, including different types of immune cells [14-19]. The adipocyte-specific role of PHB appears to be mediated through its mitochondrial functions, whereas immune cell-specific role of PHB appears to be primarily involving membrane-associated cell signaling functions $[15-17,19]$. In addition, PHB has a multifaceted relationship with sex steroid hormones, estrogens and androgens, and their receptors (reviewed in [13]). On the one hand, PHB functions as a co-repressor of sex steroid receptors, while on the other, it has been identified as a target gene under sex hormone regulation [20-23]. Most work on PHB and its association with sex steroids and their receptors have been reported in reproductive tissues such as the endometrium, mammary gland, and prostate tissues or their derivative cell lines [20-23]. However, the potential role PHB may play in mediating sex differences in non-reproductive tissues has not been investigated, despite substantial influence of sex steroids on whole body metabolism and in major metabolic tissues, including the adipose tissue, skeletal muscle, and liver tissue.

Recently, we have developed and characterized two transgenic $(\mathrm{Tg})$ obese mouse models that overexpress PHB (PHB-Tg) or a phospho-mutant PHB lacking the tyrsone-114 phosphorylation site (mPHB-Tg) from the fatty acid binding protein-4 (Fabp-4) gene promoter (reviewed in $[12,13])$. The Fabp-4 gene promoter was used for simultaneous expression of PHB or mPHB in both adipocytes and in monocytic macrophages/dendritic cells [24-26]. PHB transgenic mice developed obesity independent of diet due to mitochondrial biogenesis in adipocytes [27]. The obese and metabolic phenotypes of PHB-Tg and $\mathrm{mPHB}-\mathrm{Tg}$ mice have been reviewed recently $[12,13]$ and therefore will not be discussed here in detail. However, to put things into a
Table 1 The common and unique features of PHB and OGT, which may have a role in mediating sex differences in insulin resistance and metabolic dysregulation

- PHB and OGT interact with each other and are regulated by sex steroids. In addition, PHB functions a co-repressor of sex steroid receptors

- PHB and OGT share similar tyrosine motifs, undergo tyrosine phosphorylation in response to insulin, and negatively regulate insulin signaling

- Both interact with a number of insulin signaling intermediates

- Both localize to mitochondria and have an important role in

mitochondrial functions

- Both function as transcriptional regulators

- In addition, OGT is an X-linked gene, subject to gene dose compensation, and invariably escape from $X$ chromosome inactivation in different cell types

perspective, we will briefly point out sex differences in metabolic phenotype of the PHB-Tg and $\mathrm{mPHB}-\mathrm{Tg}$ mice wherever necessary. In brief, phenotypic characterizations of the PHB-Tg and $\mathrm{mPHB}-\mathrm{Tg}$ mice have revealed that PHB plays an important role in sex differences in adipose and immune functions [27, 28]. The sex dimorphic phenotypes in PHB-Tg and mPHB-Tg mice include male-specific obesity-related insulin resistance, low-grade chronic inflammation, and obesity-related tumors [27-29], which appear to be a consequence of the cell compartment- and cell type-specific functions of PHB. This finding provided proof that the interplay between PHB and sex steroids is not only limited to reproductive tissues, but also occurs in metabolic tissues and immune cells. This finding may have implications in human health and disease. In addition to sex steroids, PHB interacts with $O$-GlcNAc transferase (OGT; uridine diphospho- $N$-acetylglucosamine:polypeptide $\beta$ - $N$-acetylglucosaminyl transferase), an X-linked gene recently identified as a mediator for sex differences in a variety of cell types [30-32]. The role of OGT in mediating sex differences involves its cell signaling and transcriptional functions. Interestingly, PHB and OGT share many features related to their regulation and pleiotropic functions (Table 1). These evidences are suggestive of PHB as a candidate pleiotropic effector molecule in producing sex differences in adipose and immune functions.

In this mini-review, we will focus on the various attributes of PHB and the putative mechanisms that may be involved in the role of PHB in sex differences in adipose and immune functions and identify future research direction in this field. Particularly, we will discuss the known relationship of PHB with sex steroid hormones and their mitochondrial attributes. In addition, we will discuss the common features that are shared between PHB and OGT, which may have implications in mediating sex differences in insulin resistance and metabolic dysregulation. Unraveling why and how PHB overexpression in adipocytes and macrophages/dendritic cells confers resistance to obesity-related metabolic dysregulation in the females, but 
opposite in males, may open innovative sex-specific interventions for obesity, insulin resistance, and metabolic syndrome.

\section{Prohibitin and sex steroids-a multifaceted relationship}

Sex chromosomes, and by extension sex steroid hormones, play a fundamental role in sex differences in the structure, regulation, and function of different cell/tissue types in the body, [33, 34]. However, the various effector molecules that mediate or modulate the effects of sex steroids on sex differences in different tissue types are largely unknown. Emerging evidence suggests that PHB is a pleiotropic effector of sex differences in adipocytes and in monocytic macrophages/dendritic cells and has a relationship with sex steroids $[27-29,35]$. The first evidence of the association between PHB family proteins and sex steroids came from the discovery of the repressor of estrogen action (REA) as a co-repressor of estrogen receptors (ERs) [36]. Gene and protein sequence analyses revealed that REA is a homologous protein of PHB that share $>50 \%$ sequence homology $[36,37]$. As a result, REA was given the name PHB2 (with PHB then being referred to as PHB1). Subsequent studies showed that similar to PHB2, PHB also has the ER co-repressor function and was identified as a target gene for estrogen and ERs $[20,22]$. It appears that prohibitins (PHBs) and ERs form a regulatory loop to control each other's functions and to maintain tissue homeostasis [22]. Subsequently, PHB was also found to function as a co-repressor of androgen receptors (ARs) [38] and was identified as a target gene for androgen and ARs [23]. Interestingly, ERs positively regulate $\mathrm{PHB}$ whereas ARs negatively regulate $\mathrm{PHB}[22,23]$, which may have important implications in mediating sex differences. Most findings that showed a multifaceted relationship between sex steroids and PHBs came from reproductive tissues or their derivative cell lines [20-23, 38]. Until recently, it was not known whether this relationship between PHBs and sex steroids exist in other cell or tissue types.

During phenotypic characterization of the PHB-Tg obese mouse model, we found that both male and female PHB-Tg mice developed obesity. However, only male PHB-Tg mice displayed obesity-related metabolic dysregulation, such as impaired glucose homeostasis, insulin sensitivity, and hyperinsulinemia [27]. This would imply that the functional consequences of PHB-induced obesity in male and female PHB-Tg mice are different, suggesting a potential interplay between $\mathrm{PHB}$ and sex steroids in adipocytes. To the best of our knowledge, this observation is the first indication of a sex-dimorphic role of PHB in adipose tissue functions. Consistent with a dysregulated metabolic phenotype, crown-like structures in visceral adipose tissue (a sign of macrophage infiltration) and fatty livers were also found in the male PHB-Tg mice [27]. With aging, fatty liver in the male PHB-Tg mice progressed to non-alcoholic steatohepatitis (NASH), and eventually hepatocellular carcinoma (HCC) around 12 months of age [29]. These changes were not observed in female PHB-Tg mice [29], suggesting that the female sex steroid hormone potentially plays a role. Thus, PHB overexpression in adipocytes further amplified sex differences in obesity-related metabolic dysregulation, where the female mice developed resistance and the male mice became susceptible. On the other hand, the mPHB-Tg mouse model shares the sex-neutral obesity and sex-dimorphic metabolic phenotype of PHB-Tg mice, implying that the loss of the tyrosine-114 phosphorylation site in PHB does not affect its mitochondria-mediated adipogenic functions [28]. Despite these phenotypic similarities, the male mPHB-Tg mice did not develop NASH and $\mathrm{HCC}$ but instead developed lymph node tumors and splenomegaly around 6 months of age; this was again not observed in the female mPHB-Tg mice [28]. It appears that PHB-mediated sex differences are not limited to adipose tissue biology but are also present in immune functions. It is possible that pre-existing or co-existing immune conditions play a crucial role in the development and progression of obesity-related metabolic diseases. In the case of male mPHB-Tg mice, the loss of tyrosine-114 phosphorylation site altered the disease course observed in the male PHB-Tg mice. Moreover, tumor development in the male PHB-Tg and $\mathrm{mPHB}-\mathrm{Tg}$ mice provided a proof that obesity-related metabolic abnormalities, such as hyperinsulinemia, facilitate tumor development, because PHB or mPHB by itself does not lead to tumor development in the female transgenic mice [28].

Ovariectomy in the female $\mathrm{mPHB}-\mathrm{Tg}$ mice suggested a potential role of ovarian estrogens in protection from obesity-related metabolic dysregulation, as the ovariectomized mPHB-Tg mice developed impaired glucose homeostasis and insulin sensitivity similar to their male counterparts [28]. However, as estrogen replacement therapy in ovariectomized mPHB-Tg mice was not performed [28], a potential role of other ovarian factors may not be ruled out. Moreover, obesity-related metabolic abnormalities after ovariectomy were sufficient to induce tumor development in the female $\mathrm{mPHB}-\mathrm{Tg}$ mice [28]. Interestingly, ovariectomy in the female $\mathrm{mPHB}-\mathrm{Tg}$ mice prevented weight gain [28], suggesting that PHB depends on sex steroid hormones for producing obese phenotype. Sex steroids may play a modulatory role in PHB function in adipocytes, which brings an additional complexity to their multifaceted relationship. In this context, it is important to note that the loss of estrogens increases adiposity in both rodents and humans [39, 40], which was not observed in the ovariectomized $\mathrm{mPHB}-\mathrm{Tg}$ mice [28]. A similar finding was also observed in the body 
weight of ovariectomized PHB-Tg mice; however, they remained protected from metabolic dysregulation [41]. These findings indicate that ovariectomy-induced metabolic dysregulation in $\mathrm{mPHB}-\mathrm{Tg}$ mice is a conjoint manifestation of adipose and immune-associated alterations $[27,28]$. In the male PHB-Tg mice, orchiectomy stopped PHB-induced weight gain and improved metabolic homeostasis, such as glucose tolerance and insulin sensitivity [41]. This would imply that PHB functions differently in male and female adipose tissue in both the presence and absence of sex steroids. This finding may have important implications in aging-related sex differences in health and diseases, as sex steroid hormone levels change throughout an individual's life and estrogens and androgens differentially regulate PHB expression levels $[22,23]$. In other words, PHB may function differently in males and females during different stages of life. Of note, alteration in PHB levels has been found in the context of aging in various model systems [42-44] and in adipocytes from obese patients in relation to aging [45]. In Caenorhabditis elegans, PHB is a context-dependent modulator of aging [42], whereas mild caloric restriction in mice (a model for longevity) upregulates the expression of PHB in livers [45]. PHB may play a similar role in monocytic macrophages and dendritic cells, which may have contributed to the gonadectomy-induced alterations in the obesity-related metabolic phenotype in the PHB-Tg and $\mathrm{mPHB}-\mathrm{Tg}$ mice. Despite challenges associated with deciphering the relative contributions of adipocytes and macrophages/dendritic cells in phenotypic changes in the PHB-Tg and mPHB-Tg mice, these mouse models have revealed PHB as a pleiotropic effector of sex differences in adipose and immune functions. Our findings raise a number of important questions about sex differences in adipose tissue functions, insulin resistance, and metabolic dysregulation and have opened potential research topics in this field.

\section{Are the sex-dimorphic effects of PHB in adipose tissue mediated via mitochondria?}

PHB (and its homologous protein PHB2) plays a crucial role in mitochondrial biology, where it functions as a chaperone for mitochondrial proteins and phospholipids [46-48]. PHB or PHB2 overexpression enhances mitochondrial functions, whereas its knockdown compromises mitochondrial functions in cell and animal models $[16,27,49]$. In vitro, PHB overexpression in preadipocytes increases adipocyte differentiation, whereas PHB knockdown has the opposite effect on adipocyte differentiation $[14,15]$. In vivo, although both male and female PHB-Tg mice developed obesity similarly, obesity-related metabolic dysregulation was observed only in the male [27]. Thus, the sex differences in obesity-related insulin resistance and metabolic dysregulation are further widened in PHB-Tg mice. The PHB-Tg mice developed obesity because of mitochondrial biogenesis in adipocytes [27]. Based on this finding, the role of PHB in sex-dimorphic adipocyte functions may be mediated through the mitochondria. This was evidenced by adipokine analysis to which increased adiponectin and decreased leptin were found in female compared with male PHB- $\mathrm{Tg} / \mathrm{mPHB}-\mathrm{Tg}$ mice $[27,28]$. In addition, sex steroids play different roles in mitochondrial biology. For example, estrogens are generally considered to facilitate mitochondrial biogenesis [50], whereas results on testosterone function in mitochondrial biology are controversial $[51,52]$. Recently, Bajpai et al. [53] have provided proof that ARs contain mitochondrial localization signal and play a role in mitochondrial function in prostate cancer cells. Previously, a multifaceted relationship between PHB and ARs has been reported in prostate cancer cells in the context of genomic actions of androgens. It would be interesting to know whether the interplay between PHB and androgens in prostate cancer cells also occur in mitochondrial compartment. As sex steroid hormones are intrinsic to sex differences and have a multifaceted relationship with $\mathrm{PHB}$, it is likely that the interplay between PHB and sex steroids in mitochondrial biology plays a role in the sex differences in adipose tissue functions. Differential alterations in the gonadectomy-induced metabolic changes in the male and female PHB-Tg and $\mathrm{mPHB}-\mathrm{Tg}$ mice, as revealed by glucose and insulin tolerance tests $[28,41]$, indicate that this is indeed appears to be the case. It is anticipated that further investigation into the adipose tissue and monocytic macrophages/dendritic cells of PHB-Tg and mPHB-Tg mice will provide a clear understanding of the interplay between PHB, sex steroids, and mitochondria in the specific cell type. In this context, it is important to note that mitochondrial dysregulation is a common feature of obesity-related abnormalities in different metabolic tissues [54-56]. In addition to sex steroids, the role of mitochondria in sex differences in obesity-related metabolic abnormalities may involve epigenetic mechanisms. Mitochondrial DNA copy numbers have been reported to play a role in epigenetic changes in the nuclear genome [57]. PHB is known to interact with mitochondrial transcription factor A (Tfam) [58], and PHB-Tg mice have increased mitochondrial DNA copy number in the adipose tissue [27]. Moreover, a number of nuclear-encoded mitochondrial genes located on $\mathrm{X}$ chromosomes, are subject to escape from $X$ chromosome inactivation $[59,60]$, which may further contribute to sex differences in obesity-related insulin resistance and metabolic dysregulation. Thus, a combination of $\mathrm{PHB}$ and sex steroid interplay as well as escape from $\mathrm{X}$ chromosome inactivation of nuclear-coded mitochondrial gene/proteins may contribute to sex differences in metabolic health and disease. 


\section{OGT and PHB - potential partners in mediating sex differences in insulin resistance and metabolic dysregulation}

OGT is a glycosyltransferase that catalyzes the addition of a single GlcNAc molecule in $O$-glycosidic linkage to serine or threonine residues (O-GlcNAcylation) in a diverse array of proteins. It is a reversible posttranslational modification at the serine and threonine residues mediated by the GlcNAc cycling enzymes OGT and $O$-GlcNAc amidase (OGA) [61]. O-GlcNAcylation often occurs at the site of, or proximal to, the same serine and threonine residues modified by kinases [61], and this competition permits a dynamic interplay that can alter signaling and protein functions [61-63]. Recent evidence suggests that OGT is a pleiotropic effector that mediates sex-dimorphic functions [30-32]. For example, sex differences in placental OGT mediate the effects of prenatal stress on neurodevelopmental programming [30]. Subsequently, canonically repressive epigenetic modification H3K27me3 (tri-methylation of lysine-27 on histone $\mathrm{H} 3$ subunit) was identified as one mechanism wherein sex differences in OGT confer variation in vulnerability to prenatal insults via establishing sex-specific trophoblast gene expression patterns [31]. It has been shown that high levels of H3K27me3 in the female placenta create resilience to the altered hypothalamic programming associated with prenatal stress exposure [31]. Notably, the OGT gene is located on the X chromosome in both human and mice [32] and is known to be under the control of dosage compensation mechanisms $[64,65]$. In addition, OGT has been identified among genes that invariably escape from $\mathrm{X}$ chromosome inactivation $(\mathrm{XCI})$ in different cell or tissue types [66]. However, the gene encoding OGA is not present on the $\mathrm{X}$ chromosome. Thus, a differential expression levels, or the ratio of the $O$-GlcNAc cycling enzymes, OGT, and OGA, may exist in male and female tissues, which could contribute to sex differences in cell signaling and transcriptional regulation, as well as mitochondrial functions. This is because in addition to cell signaling functions, OGT is a transcriptional regulator that could regulate diverse expression networks [32] and localizes to mitochondria, where it plays a role in the regulation of mitochondrial structure and functions [67]. In the context of cell signaling, it is important to note that a number of insulin signaling intermediates undergo $O$-GlcNAcylation, which plays a role in insulin resistance [68-71]. For example, the $O$-GlcNAcylation of insulin receptor substrate-1 (IRS1) occurs within or in close proximity of tyrosine phosphorylation sites, which are involved in the interaction between IRS1 and phosphoinositide 3-kinase (PI3K) [68, 69, 71]. The $O$-GlcNAcylation of IRS1 has been shown to interfere with its interaction with PI3K and attenuate insulin signaling downstream of the IRS1 $[68,69,71]$. In addition to
O-GlcNAcylation, the phosphorylation of IRS1 by an inhibitor of nuclear factor kappa-B kinase subunit beta $(\mathrm{IKK} \beta)$, protein kinase $\mathrm{C}(\mathrm{PKC})$, and $\mathrm{c}$-Jun $\mathrm{N}$-terminal kinase (JNK) at serine residues has been reported to negatively regulate insulin signaling [72]. However, it is not known whether the serine phosphorylation of IRS1 that is involved in inducing insulin resistance is also subjected to $O$-GlcNAcylation. Thus, a possibility exists that the $O$-GlcNAcylation of such residues may prevent their negative effects on insulin signaling and may be differentially regulated in male and female due to escape of OGT from the XCI.

In addition to insulin resistance, mitochondrial dysregulation in metabolic tissues is a well-established feature of obesity-associated insulin resistance and metabolic dysregulation [54-56]. Notably, the O-GlcNAcylation of mitochondrial proteins has been implicated in obesity and hyperglycemia-related mitochondrial dysregulation $[73,74]$. However, it is not known whether differential $O$-GlcNAcylation of insulin signaling intermediates and mitochondrial proteins play a role in sex differences in insulin resistance and metabolic dysregulation. Recently, OGT-related mitochondrial motility has been shown to be associated with sex differences and exercise effects in depression induced by prenatal exposure to glucocorticoids [75]. Moreover, the $O$-GlcNAcylation of a number of proteins in cardiomyocytes has been reported to have protective effects from ischemia-perfusion injury [76, 77]. Sex differences are known to exist in cardiovascular diseases [78, 79], which is a major complication of obesity and type 2 diabetes. It would be interesting to know if the OGT escape from the XCI in different metabolic tissues, which play a role in sex differences in cellular functions, either directly as a transcriptional regulator, or through the O-GlcNAcylation of cell signaling and mitochondrial proteins.

\section{Does alternate 0 -GIcNAcylation and phosphorylation of PHB at common sites play a role in sex-dimorphic functions?}

Previously, we have shown that PHB physically interacts with OGT and is $O$-GlcNAcylated at the serine-121 and threonine-258 residues [80]. Moreover, PHB undergoes tyrosine phosphorylation in response to insulin stimulation, which in turn negatively regulates insulin signaling in multiple cell types [81, 82]. The tyrosine phosphorylation sites (tyrosine-114 and tyrosine-259) and the O-GlcNAcylation sites (serine-121 and threonine-258) in PHB are in close proximity, and they regulate each other [80]. The tyrosine phosphorylation of PHB facilitates $O$-GlcNAcylation, whereas O-GlcNAcylation has the opposite effect on tyrosine phosphorylation [80]. Interestingly, threonine-258 in PHB is an Akt (protein kinase B) phosphorylation site, which positively regulates insulin 
signaling through a process that involves its interaction with phosphatidylinositol (3,4,5)-triphosphate [82, 83]. Similarly, the threonine-308 phosphorylation site in Akt, which is required for Akt activation, is also subjected to O-GlcNAcylation [70] and potentially contributes to the development of insulin resistance. Thus, a possibility exists that alternate phosphorylation and $O$-GlcNAcylation of insulin signaling intermediates, including $\mathrm{PHB}$, at common sites or adjacent sites may cause sex differences in insulin resistance and consequently metabolic dysregulation. Of note, similar to PHB, OGT also undergoes tyrosine phosphorylation and $O$-GlcNAcylation in response to insulin, and tyrosine phosphorylation enhances $O$-GlcNAc transferase activity, which in turn negatively regulates insulin signaling [71]. Moreover, PHB and OGT are target genes for androgen receptors [23, 84], and both interact with a number of epigenetic and transcriptional regulators [85-91], play a role in the regulation of sex differences in a number of cell or tissue types, and contain similar tyrosine motifs [80]. For example, OGT has been found to complex with ten-eleven translocation proteins-1,2,3 (TET1,2,3) that regulators of DNA demethylation [85, 86], transcriptional repressors SIN3A and histone deacetylases [87], transcriptional activator HCF-1 (host cell factor-1) [88], histone methyltransferase MLL5 (mixed lineage leukemia-5) [89], and modify histone tails [90, 91]. In addition, ERs are known to interact with OGT and undergo O-GlcNAcylation (including alternate phosphorylation and $O$-GlcNAcylation at the same residue), which influence their transcriptional activities [92, 93]. Similarly, PHB functions as a transcriptional co-regulator with BRG1 (brahma-related gene-1), HDAC1 (histone deacetylase-1), and p300 (histone acetyltransferase p300), as well as a co-repressor of androgen and estrogen receptors [94, 95]. Although PHB clearly acts as a key transcriptional regulator, how PHB itself is regulated remains largely unknown. Theiss et al. [96] have shown that the PHB gene promoter contains functional interleunin-6 (IL-6) response element, and we have found that insulin regulates PHB expression in adipocytes [14]. Thus, PHB expression and functions may be altered in obesity and obesity-related abnormalities, such as insulin resistance and low-grade chronic inflammation. Furthermore, accumulating evidence suggests that PHB and OGT play an important role in different immune cell types [27-32, 97] and OGT is highly expressed in lymphocytes and lymphoid tissues [32, 98, 99]. Thus, PHB and OGT may be a part of sex steroid signaling in metabolic tissues and in the regulation of insulin signaling in a sex-specific manner. PHB and OGT may also be regulated concurrently at the transcriptional and protein levels, which may contribute to sex differences in metabolic and immune functions.

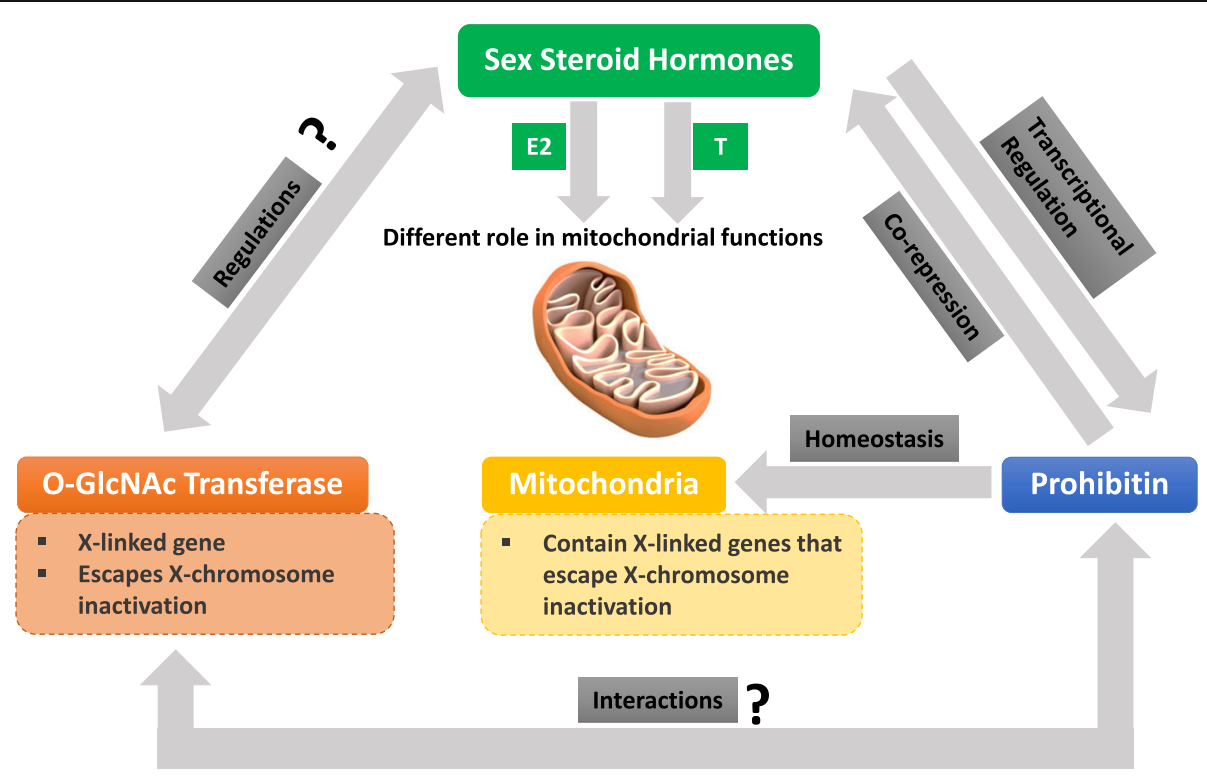

Sex Differences in Obesity, Insulin Resistance and Metabolic Dysregulation

Fig. 1 Schematic of potential interplay between sex steroid hormones, prohibitin, O-GIcNAc transferase, and mitochondria in the sex difference in obesity, insulin resistance, and metabolic dysregulation. Sex steroid hormones differentially regulate mitochondrial biology; E2 and T regulate prohibitin at the transcription level; and prohibitin in turn acts as co-repressor of sex steroid actions. Prohibitin is essential for maintaining mitochondrial homeostasis. O-GlcNac transferase and some of the nuclear-encoded mitochondrial genes are X-linked and can escape $X$ chromosome inactivation. O-GlcNac transferase shares similar features as prohibitin and may be subject to regulation by sex steroid hormones. E2 estradiol, T testosterone 


\section{Does PHB2 have a role in sex differences in obesity, insulin resistance, and metabolic dysregulation?}

Some of the pleiotropic attributes of PHB is also shared by its homologous protein PHB2 [12, 18], including a number of phosphorylation sites that have been implicated in their cell signaling functions and intracellular trafficking [100, 101]. For examples, PHBs have been shown to play a crucial role in pancreatic beta cell function $[48,102]$ and in the maturation of T cells [18]. Despite similarities between PHB and PHB2, their functions do not appear to be redundant or compensated by each other. Rather, the knockdown or deletion of one member often leads to substantial decrease in the protein level of other members $[15,48,103,104]$. However, to the best of our knowledge, a role of PHB2 in sex differences has not been reported. As PHBs form heterodimers in the inner mitochondrial membrane, play a crucial role in mitochondrial biology, and have multifaceted relationship with sex steroids and their receptors, it is possible that PHB2 has sex-dimorphic functions, which requires further investigation.

\section{Conclusion}

Sex differences are fundamental to the biology and pathobiology of human health and disease, and these differences are apparent in adipose and immune functions. However, this basic tenet of human adipose and immune functions has not yet been capitalized for the development of sex-based therapeutics for more effective treatment outcomes. A major hurdle has been our poor knowledge of effector molecules, which mediate these differences in health and disease. The discovery of the pleiotropic attributes of PHB and OGT in mediating sex differences in different cell or tissue types is a step forward in remediating this. There are a number of potential mechanisms, which may work in a cell compartment- and cell type-specific manner; however, a bi-faceted relationship between PHB and sex steroids appears to be central to it (Fig. 1). This unique relationship between PHB and sex steroids may increase the likelihood of targeting PHB for sex-based precision medicine, especially for obesity-related metabolic diseases. In addition to adipocytes and monocytes (macrophage and dendritic cells), PHBs play a role in pancreatic beta cells, lymphocytes, and mast cells [17-19]. We anticipate that decoding the complex relationship between the PHBs and sex steroids in different cellular compartments and cell types will lead to new insights into the underlying mechanisms and sex-specific therapeutic opportunity. Targeting these pathways would help to build a fresh approach that will contribute to innovative regimens for the sex-specific prevention and treatment of obesity, insulin resistance, and metabolic syndromes.

\begin{abstract}
Abbreviations
Akt: Protein kinase B; AR: Androgen receptors; BRG1: Brahma-related gene-1; E2: Estradiol; ER: Estrogen receptors; Fabp4: Fatty acid binding protein-4; H3K27me3: Trimethylation of lysine-27 on histone H3 subunit;

HCC: Hepatocellular carcinoma; HCF1: Host cell factor 1; HDAC1: Histone deacetylase 1; IKKß: Inhibitor of nuclear factor kappa-B kinase subunit beta; IRS1: Insulin receptor substrate 1; JNK: c-Jun N-terminal kinase; MLL5: Mixed lineage leukemia 5; mPHB-Tg: Mutant PHB-Tg mouse model; NASH: Nonalcoholic steatohepatitis; OGA: O-GlcNAc amidase; O-GlcNAcylation: Protein modification at serine or threonine residue by $\mathrm{O}$-linked $\mathrm{N}$-acetylglucosamine; OGT: O-GICNAc transferase (uridine diphospho- $N$ -

acetylglucosamine:polypeptide $\beta$ - $N$-acetylglucosaminyltransferase); p300: Histone acetyltransferase p300; PHB : Prohibitin; PHB2: Prohibitin 2; PHBs: Prohibitin (also known as prohibitin-1) and prohibitin-2; PHB-Tg: An obese mouse model developed by prohibitin-induced mitochondrial remodeling in adipocytes and macrophages/dendritic cells; PI3K: Phosphoinositide 3-kinase; PKC: Protein kinase C; REA: Repressor of estrogen activity;

SIN3A: SIN3 transcription regulator family member A; T: Testosterone;

Tafm: Mitochondrial transcription factor A; TET1, 2, 3: Ten-eleven

translocation proteins-1, 2, 3; Tg: Transgenic; XCl: X chromosome inactivation
\end{abstract}

Acknowledgements

The authors would like to thank Nivida Mishra for editing this manuscript.

\section{Funding}

SM is supported by funds from the Natural Sciences and Engineering Research Council (NSERC, RGPIN-2017-04962), Research Manitoba, and Health Sciences Centre Foundation. YXZX is a recipient of the University of Manitoba Graduate Fellowship (UMGF) and Alexander Graham Bell Canada Graduate Scholarship Doctoral (CGS D) from NSERC.

Availability of data and materials

Not applicable.

Authors' contributions

All authors contributed in manuscript writing. All authors read and approved the final manuscript.

Ethics approval and consent to participate

Not applicable.

Consent for publication

Not applicable.

\section{Competing interests}

The authors declare that they have no competing interests.

\section{Publisher's Note}

Springer Nature remains neutral with regard to jurisdictional claims in published maps and institutional affiliations.

Received: 11 February 2019 Accepted: 9 May 2019

Published online: 22 May 2019

\section{References}

1. Ng M, Fleming T, Robinson M, Thomson B, Graetz N, Margono C, et al. Global, regional, and national prevalence of overweight and obesity in children and adults during 1980-2013: a systematic analysis for the Global Burden of Disease Study 2013. Lancet. 2014;384(9945):766-81.

2. Ansaldo AM, Montecucco F, Sahebkar A, Dallegri F, Carbone F. Epicardial adipose tissue and cardiovascular diseases. Int J Cardiol. 2019;278:254-60.

3. Arnold M, Pandeya N, Byrnes G, Renehan PAG, Stevens GA, Ezzati PM, Ferlay J, Miranda JJ, Romieu I, Dikshit R, et al. Global burden of cancer attributable to high body-mass index in 2012: a population-based study. Lancet Oncol. 2015;16:36-46. https://doi.org/10.1016/S1470-2045(14)71123-4.

4. Chan KL, Cathomas F, Russo SJ. Central and peripheral inflammation link metabolic syndrome and major depressive disorder. Physiology (Bethesda). 2019;34(2):123-33.

5. Daryabor G, Kabelitz D, Kalantar K. An update on immune dysregulation in obesity-related insulin resistance. Scand J Immunol. 2018;28:e12747. 
6. Martyniak K, Masternak MM. Changes in adipose tissue cellular composition during obesity and aging as a cause of metabolic dysregulation. Exp Gerontol. 2017;94:59-63.

7. Ross R, Shaw KD, Rissanen J, Martel Y, de Guise J, Avruch L. Sex differences in lean and adipose tissue distribution by magnetic resonance imaging: anthropometric relationships. Am J Clin Nutr. 1994;59:1277-85.

8. Fried SK, Kral JG. Sex differences in regional distribution of fat cell size and lipoprotein lipase activity in morbidly obese patients. Int J Obes. 1987;11:129-40

9. Whitacre CC. Sex differences in autoimmune disease. Nat Immunol. 2001;2:777-80.

10. Guerra-Silveira F, Abad-Franch F. Sex bias in infectious disease epidemiology: patterns and processes. PLoS One. 2013;8:e62390.

11. Markle JG, Fish EN. SeXX matters in immunity. Trends Immunol. 2014; 35:97-104.

12. Ande SR, Nguyen KH, Nyomba BLG, Mishra S. Prohibitin in adipose and immune functions. Trends Endocrinol Metab. 2016;27:531-41.

13. Mishra S, Nyomba BG. Prohibitin - at the crossroads of obesity-linked diabetes and cancer. Exp Biol Med (Maywood). 2017;242:1170-7.

14. Ande $S R, X u Z$, Gu Y, Mishra S. Prohibitin has an important role in adipocyte differentiation. Int J Obes. 2012;36(9):1236-44.

15. Liu D, Lin Y, Kang T, Huang B, Xu W, Garcia-Barrio M, Olatinwo M, Matthews $\mathrm{R}$, Chen YE, Thompson WE. Mitochondrial dysfunction and adipogenic reduction by prohibitin silencing in 3T3-L1 cells. PLoS One. 2012;7(3):e34315.

16. Kang T, Lu W, Xu W, Anderson L, Bacanamwo M, Thompson W, Chen YE, Liu D. MicroRNA-27 (miR-27) targets prohibitin and impairs adipocyte differentiation and mitochondrial function in human adipose-derived stem cells. J Biol Chem. 2013;288:34394-402.

17. Lucas CR, Cordero-Nieves HM, Erbe RS, McAlees JW, Bhatia S, Hodes RJ, Campbell KS, Sanders VM. Prohibitins and the cytoplasmic domain of CD86 cooperate to mediate CD86 signaling in B lymphocytes. J Immunol. 2013; 190:723-36.

18. Ross JA, Nagy ZS, Kirken RA. The PHB1/2 phosphocomplex is required for mitochondrial homeostasis and survival of human T cells. J Biol Chem. 2008; 283:4699-713

19. Kim DK, Kim HS, Kim AR, et al. The scaffold protein prohibitin is required for antigen-stimulated signaling in mast cells. Sci Signal. 2013;6:ra80.

20. He B, Feng Q, Mukherjee A, Lonard DM, DeMayo FJ, Katzenellenbogen BS, Lydon JP, O'Malley BW. A repressive role for prohibitin in estrogen signaling. Mol Endocrinol. 2008;22(2):344-60.

21. Park SE, XU J, Frolova A, Liao L, O'Malley BW, Katzenellenbogen BS. Genetic deletion of the repressor of estrogen receptor activity (REA) enhances the response to estrogen in target tissues in vivo. Mol Cell Biol. 2005;25(5):1989-99.

22. He B, Kim TH, Kommagani R, Feng Q, Lanz RB, Jeong JW, DeMayo FJ, Katzenellenbogen BS, Lydon JP, O'Malley BW. Estrogen-regulated prohibitin is required for mouse uterine development and adult function. Endocrinology. 2011;152(3):1047-56

23. Gamble SC, Chotai D, Odontiadis M, Dart DA, Brooke GN, Powell SM, Reebye V, Varela-Carver A, Kawano Y, Waxman J, Bevan CL. Prohibitin, a protein downregulated by androgens, represses androgen receptor activity. Oncogene. 2007;26(12):1757-68.

24. Fu Y, Luo L, Luo N, Garvey WT. Lipid metabolism mediated by adipocyte lipid binding protein (ALBP/aP2) gene expression in human THP-1 macrophages. Atherosclerosis. 2006;188:102-11.

25. Kusminski CM, Holland WL, Sun K, et al. MitoNEET-driven alterations in adipocyte mitochondrial activity reveal a crucial adaptive process that preserves insulin sensitivity in obesity. Nat Med. 2012;18:1539-49.

26. Rolph MS, et al. Regulation of dendritic cell function and T cell priming by the fatty acid binding protein AP2. J Immunol. 2006;177:7794-801.

27. Ande SR, Nguyen KH, Padilla-Meier GP, Wahida W, Nyomba BL, Mishra S. Prohibitin overexpression in adipocytes induces mitochondrial biogenesis, leads to obesity development, and affects glucose homeostasis in a sexspecific manner. Diabetes. 2014;63:3734-41.

28. Ande SR, Nguyen KH, Padilla-Meier GP, Nyomba BL, Mishra S. Expression of a mutant prohibitin from the aP2 gene promoter leads to obesity-linked tumor development in insulin resistance-dependent manner. Oncogene. 2016:35:4459-70.

29. Ande SR, Nguyen KH, Grégoire Nyomba BL, Mishra S. Prohibitin-induced, obesity-associated insulin resistance and accompanying low-grade inflammation causes NASH and HCC. Sci Rep. 2016;6:23608.
30. Howerton $\mathrm{CL}$, Morgan CP, Fischer DB, Bale TL. O-GlcNAc transferase (OGT) as a placental biomarker of maternal stress and reprogramming of CNS gene transcription in development. Proc Natl Acad Sci U S A. 2013;110(13):5169-74.s.

31. Nugent BM, O'Donnell CM, Epperson CN, Bale TL. Placental H3K27me3 establishes female resilience to prenatal insults. Nat Commun. 2018;9(1):2555.

32. Abramowitz LK, Olivier-Van Stichelen S, Hanover JA. Chromosome imbalance as a driver of sex disparity in disease. J Genomics. 2014;2:77-88. https://doi.org/10.7150/jgen.8123.

33. Mauvais-Jarvis F. Sex differences in metabolic homeostasis, diabetes, and obesity. Biol Sex Differ. 2015;6:14.

34. Fish EN. The X-files in immunity: sex-based differences predispose immune responses. Nat Rev Immunol. 2008:8:737-44.

35. Nguyen $\mathrm{KH}$, Ande SR, Mishra S. Obesity-related abnormalities couple environmental triggers with genetic susceptibility in adult-onset T1D. Biochem Biophys Res Commun. 2016;470:94-100.

36. Montano MM, Ekena K, Delage-Mourroux R, Chang W, Martini P, Katzenellenbogen BS. An estrogen receptor-selective coregulator that potentiates the effectiveness of antiestrogens and represses the activity of estrogens. Proc Natl Acad Sci U S A. 1999;96(12):6947-52.

37. Coates PJ, Jamieson DJ, Smart K, Prescott AR, Hall PA. The prohibitin family of mitochondrial proteins regulate replicative lifespan. Curr Biol. 1997:7(8):607-10.

38. Dart DA, Spencer-Dene B, Gamble WJ, Bevan CL. Manipulating prohibitin levels provides evidence for an in vivo role in androgen regulation of prostate tumors. Endocr Relat Cancer. 2009;16(4):1157-69.

39. Ohlsson C, Hellberg N, Parini P, Vidal O, Bohlooly-Y M, Rudling M, Lindberg MK, Warner M, Angelin B, Gustafsson JA. Obesity and disturbed lipoprotein profile in estrogen receptor-alpha-deficient male mice. Biochem Biophys Res Commun. 2000;278(3):640-5.

40. Toth MJ, Tchernof A, Sites CK, Poehlman ET. Effect of menopausal status on body composition and abdominal fat distribution. Int J Obes Relat Metab Disord. 2000;24:226-31.

41. Xu YXZ, Ande SR, Mishra S. Gonadectomy in Mito-Ob mice revealed a sexdimorphic relationship between prohibitin and sex steroids in adipose tissue biology and glucose homeostasis. Biol Sex Differ. 2018;9:37.

42. Lourenço AB, Muñoz-Jiménez C, Venegas-Calerón M, Artal-Sanz M. Analysis of the effect of the mitochondrial prohibitin complex, a context-dependent modulator of longevity, on the C. elegans metabolome. Biochim Biophys Acta. 2015;1847(11):1457-68.

43. Miwa S, Jow H, Baty K, Johnson A, Czapiewski R, Saretzki G, Treumann A, von Zglinicki T. Low abundance of the matrix arm of complex I in mitochondria predicts longevity in mice. Nat Commun. 2014;5:3837.

44. Takahashi S, Masuda J, Shimagami H, Ohta Y, Kanda T, Saito K, Kato H. Mild caloric restriction up-regulates the expression of prohibitin: a proteome study. Biochem Biophys Res Commun. 2011;405(3):462-7.

45. Alfadda AA, Benabdelkamel H, Masood A, Moustafa A, Sallam R, Bassas A, Duncan M. Proteomic analysis of mature adipocytes from obese patients in relation to aging. Exp Gerontol. 2013;48(11):1196-203.

46. Nijtmans LG, de Jong L, Artal Sanz M, Coates PJ, Berden JA, Back JW, Muijsers AO, van der Spek $H$, Grivell LA. Prohibitins act as a membranebound chaperone for the stabilization of mitochondrial proteins. EMBO J. 2000;19:2444-51.

47. Hernando-Rodríguez B, Artal-Sanz M. Mitochondrial quality control mechanisms and the PHB (prohibitin) complex. Cells. 2018;7(12):238,

48. Supale S, Thorel F, Merkwirth C, Gjinovci A, Herrera PL, Scorrano L, Meda P, Langer T, Maechler P. Loss of prohibitin induces mitochondrial damages altering $\beta$-cell function and survival and is responsible for gradual diabetes development. Diabetes. 2013;62(10):3488-99.

49. Merkwirth C, Martinelli P, Korwitz A, Morbin M, Brönneke HS, Jordan SD, Rugarli El, Langer T. Loss of prohibitin membrane scaffolds impairs mitochondrial architecture and leads to tau hyperphosphorylation and neurodegeneration. PLoS Genet. 2012:8:e1003021.

50. Galmés-Pascual BM, Nadal-Casellas A, Bauza-Thorbrügge M, Sbert-Roig M, García-Palmer FJ, Proenza AM, Gianotti M, Lladó I. 17ß-estradiol improves hepatic mitochondrial biogenesis and function through PGC1B. J Endocrinol. 2017;232(2):297-308.

51. Capllonch-Amer G, Lladó I, Proenza AM, García-Palmer FJ, Gianotti MJ. Opposite effects of 17- $\beta$ estradiol and testosterone on mitochondrial biogenesis and adiponectin synthesis in white adipocytes. Mol Endocrinol. 2014;52(2):203-14. https://doi.org/10.1530/JME-13-0201. 
52. Usui T, et al. Elevated mitochondrial biogenesis in skeletal muscle is associated with testosterone-induced body weight loss in male mice. FEBS Lett. 2014;588(10):1935-41.

53. Bajpai P, Koc E, Sonpavde G, Singh R, Singh KK. Mitochondrial localization, import, and mitochondrial function of the androgen receptor. J Biol Chem. 2019;294(16):6621-34.

54. Zamora-Mendoza R, Rosas-Vargas H, Ramos-Cervantes MT, Garcia-Zuniga P, Perez-Lorenzana H, Mendoza-Lorenzo P, Perez-Ortiz AC, Estrada-Mena FJ, Miliar-Garcia A, Lara-Padilla E, Ceballos G, Rodriguez A, Villarreal F, RamirezSanchez I. Dysregulation of mitochondrial function and biogenesis modulators in adipose tissue of obese children. Int J Obes. 2018:42:618-24

55. Hino K, Nishina S, Sasaki K, Hara Y. Mitochondrial damage and iron metabolic dysregulation in hepatitis C virus infection. Free Radic Biol Med. 2019;133:193-99.

56. King AL, Mantena SK, Andringa KK, Millender-Swain T, Dunham-Snary KJ Oliva CR, Griguer CE, Bailey SM. The methyl donor S-adenosylmethionine prevents liver hypoxia and dysregulation of mitochondrial bioenergetic function in a rat model of alcohol-induced fatty liver disease. Redox Biol. 2016:9:188-97.

57. Smiraglia D, Kulawiec M, Bistulfi GL, Ghoshal S, Singh KK. A novel role for mitochondria in regulating epigenetic modification in the nucleus. Cancer Biol Ther. 2008;7:1182-90.

58. Kasashima K, Sumitani M, Satoh M, Endo H. Human prohibitin 1 maintains the organization and stability of the mitochondrial nucleoids. Exp Cell Res. 2008;314:988-96

59. Balaton BP, Cotton AM, Brown CJ. Derivation of consensus inactivation status for X-linked genes from genome-wide studies. Biol Sex Differ. 2015;6:35.

60. Mishra S, Nyomba BG. Prohibitin: a hypothetical target for sex-based new therapeutics for metabolic and immune diseases. Exp Biol Med (Maywood). 2019 Feb;4:1535370219828362. https://doi.org/10.1177/1535370219828362.

61. Bond MR, Hanover JA. A little sugar goes a long way: the cell biology of OGlcNAc. J Cell Biol. 2015:208:869-80.

62. Ramakrishnan P, Clark PM, Mason DE, et al. Activation of the transcriptional function of the NF-kB protein c-Rel by O-GlcNAc glycosylation. Sci Signal. 2013;6:ra75

63. Hart GW, Slawson C, Ramirez-Correa G, Lagerlof O. Cross talk between OGlcNAcylation and phosphorylation: roles in signaling, transcription, and chronic disease. Annu Rev Biochem. 2011:80:825-58.

64. Brown CJ, Lafreniere RG, Powers VE, Sebastio G, Ballabio A, Pettigrew AL, et al. Localization of the $X$ inactivation centre on the human $X$ chromosome in Xq13. Nature. 1991;349:82-4. https://doi.org/10.1038/349082a0.

65. Lin H, Gupta V, VerMilyea MD, Falciani F, Lee JT, O'Neill LP, et al. Dosage compensation in the mouse balances up-regulation and silencing of $X$ linked genes. PLoS Biol. 2007;5:e326. https://doi.org/10.1371/journal.pbio. 0050326.

66. Carrel L, Willard HF. X-inactivation profile reveals extensive variability in $\mathrm{X}$ linked gene expression in females. Nature. 2005;434:400-4.

67. Tan EP, McGreal SR, Graw S, Tessman R, Koppel SJ, Dhakal P, Zhang Z, Machacek M, Zachara NE, Koestler DC, Peterson KR, Thyfault JP, Swerdlow RH, Krishnamurthy P, DiTacchio L, Apte U, Slawson C. Sustained OGlcNAcylation reprograms mitochondrial function to regulate energy metabolism. J Biol Chem. 2017;292(36):14940-62.

68. Klein AL, Berkaw MN, Buse MG, Ball LE. O-linked N-acetylglucosamine modification of insulin receptor substrate-1 occurs in close proximity to multiple SH2 domain binding motifs. Mol Cell Proteomics. 2009;8(12): 2733-45.

69. Whelan SA, Dias WB, Thiruneelakantapillai L, Lane MD, Hart GW. Regulation of insulin receptor substrate 1 (IRS-1)/AKT kinase-mediated insulin signaling by O-linked beta-N-acetylglucosamine in 3T3-L1 adipocytes. J Biol Chem 2010;285(8):5204-11.

70. Park SY, Ryu J, Lee W. O-GlcNAc modification on IRS-1 and Akt2 by PUGNAC inhibits their phosphorylation and induces insulin resistance in rat primary adipocytes. Exp Mol Med. 2005;37(3):220-9.

71. Yang $X$, Ongusaha PP, Miles PD, et al. Phosphoinositide signalling links OGICNAc transferase to insulin resistance. Nature. 2008;451:964-9.

72. Czech MP. Insulin action and resistance in obesity and type 2 diabetes. Nat Med. 2017;23(7):804-14.

73. Ma J, Banerjee P, Whelan SA, Liu T, Wei AC, Ramirez-Correa G, McComb ME, Costello CE, O'Rourke B, Murphy A, Hart GW. Comparative proteomics reveals dysregulated mitochondrial O-GlcNAcylation in diabetic hearts. J Proteome Res. 2016;15(7):2254-64.
74. Gu Y, Ande SR, Mishra S. Altered O-GIcNAc modification and phosphorylation of mitochondrial proteins in myoblast cells exposed to high glucose. Arch Biochem Biophys. 2011;505(1):98-104

75. Liu W, Wang H, Xue X, Xia J, Liu J, Qi Z, Ji L. OGT-related mitochondrial motility is associated with sex differences and exercise effects in depression induced by prenatal exposure to glucocorticoids. J Affect Disord. 2018;226:203-15.

76. Zafir A, Readnower R, Long BW, McCracken J, Aird A, Alvarez A, Cummins TD, Li Q, Hill BG, Bhatnagar A, Prabhu SD, Bolli R, Jones SP. Protein OGlcNAcylation is a novel cytoprotective signal in cardiac stem cells. Stem Cells. 2013;31(4):765-75.68.

77. Darley-Usmar VM, Ball LE, Chatham JC. Protein O-linked $\beta-\mathrm{N}$ acetylglucosamine: a novel effector of cardiomyocyte metabolism and function. J Mol Cell Cardiol. 2012;52(3):538-49.

78. Humphries KH, Izadnegahdar M, Sedlak T, Saw J, Johnston N, SchenckGustafsson K, Shah RU, Regitz-Zagrosek V, Grewal J, Vaccarino V, Wei J, Bairey Merz CN. Sex differences in cardiovascular disease - impact on care and outcomes. Front Neuroendocrinol. 2017;46:46-70.

79. Regitz-Zagrosek V, Kararigas G. Mechanistic pathways of sex differences in cardiovascular disease. Physiol Rev. 2017;97(1):1-37.

80. Ande SR, Moulik S, Mishra S. Interaction between O-GlcNAc modification and tyrosine phosphorylation of prohibitin: implication for a novel binary switch. PLoS One. 2009;4(2):e4586.

81. Ande SR, Gu Y, Nyomba BLG, Mishra S. Insulin induced phosphorylation of prohibitin at tyrosine114 recruits Shp1. Biochim Biophy Acta-Mole Cell Research. 2009:1793:1372-8.

82. Ande SR, Mishra S. Prohibitin interacts with phosphatidylinositol 3,4,5triphosphate (PIP3) and modulates insulin signaling. Biochem Biophys Res Commun. 2009;390:1023-8.

83. Han EK, Mcgonigal T, Butler C, et al. Characterization of Akt overexpression in MiaPaCa-2 cells: prohibitin is an Akt substrate both in vitro and in cells. Anticancer Res. 2008:28:957-63.

84. Itkonen HM, Minner S, Guldvik IJ, Sandmann MJ, Tsourlakis MC, Berge V, Svindland A, Schlomm T, Mills IG. O-GICNAc transferase integrates metabolic pathways to regulate the stability of c-MYC in human prostate cancer cells. Cancer Res. 2013:73(16):5277-87.

85. Chen Q, Chen Y, Bian C, Fujiki R, Yu X. TET2 promotes histone OGlcNAcylation during gene transcription. Nature. 2013:493:561-4. https://doi. org/10.1038/nature11742.

86. Vella P, Scelfo A, Jammula S, Chiacchiera F, Williams K, Cuomo A, et al. Tet proteins connect the O-linked $\mathrm{N}$-acetylglucosamine transferase Ogt to chromatin in embryonic stem cells. Mol Cell. 2013;49:645-56. https://doi. org/10.1016/j.molcel.2012.12.019.

87. Yang X, Zhang F, Kudlow JE. Recruitment of O-GICNAc transferase to promoters by corepressor mSin3A: coupling protein O-GlcNAcylation to transcriptional repression. Cell. 2002;110:69-80.

88. Capotosti F, Guernier S, Lammers F, Waridel P, Cai Y, Jin J, et al. O-GlcNAc transferase catalyzes site-specific proteolysis of HCF-1. Cell. 2011;144:376-88. https://doi.org/10.1016/j.cell.2010.12.030.

89. Fujiki R, Chikanishi T, Hashiba W, Ito H, Takada I, Roeder RG, et al. GlcNAcylation of a histone methyltransferase in retinoic-acid-induced granulopoiesis. Nature. 2009;459:455-9. https://doi.org/10.1038/nature07954.

90. Zhu G, Tao T, Zhang D, Liu X, Qiu H, Han L, Xu Z, Xiao Y, Cheng C, Shen A. O-GlcNAcylation of histone deacetylases 1 in hepatocellular carcinoma promotes cancer progression. Glycobiology. 2016;26(8):820-33.

91. Xu Q, Yang C, Du Y, Chen Y, Liu H, Deng M, Zhang H, Zhang L, Liu T, Liu Q, Wang L, Lou Z, Pei H. AMPK regulates histone H2B O-GlcNAcylation. Nucleic Acids Res. 2014;42(9):5594-604

92. Cheng X, Hart GW. Alternative O-glycosylation/O-phosphorylation of serine16 in murine estrogen receptor beta: post-translational regulation of turnover and transactivation activity. J Biol Chem. 2001;276(13):10570-5.

93. Cheng X, Cole RN, Zaia J, Hart GW. Alternative O-glycosylation/Ophosphorylation of the murine estrogen receptor beta. Biochemistry. 2000:39(38):11609-20.

94. Dai Y, Ngo D, Jacob J, Forman LW, Faller DV. Prohibitin and the SWI/SNF ATPase subunit BRG1 are required for effective androgen antagonistmediated transcriptional repression of androgen receptor-regulated genes. Carcinogenesis, 2008:29(9):1725-33.

95. Wang S, Fusaro G, Padmanabhan J, Chellappan SP. Prohibitin co-localizes with $\mathrm{Rb}$ in the nucleus and recruits $\mathrm{N}-\mathrm{COR}$ and HDAC1 for transcriptional repression. Oncogene. 2002;21:8388-96. 
96. Theiss AL, Obertone TS, Merlin D, Sitaraman SV. Interleukin-6

transcriptionally regulates prohibitin expression in intestinal epithelial cells. J Biol Chem. 2007;282(17):12804-12.

97. Terashima M, Kim KM, Adachi T, et al. The IgM receptor of $B$ lymphocytes is associated with prohibitin and a prohibitin-related protein. EMBO J. 1994;13:3782-92.

98. Abramowitz LK, Hanover JA. T cell development and the physiological role of O-GICNAc. FEBS Lett. 2018;592(23):3943-9.

99. Wu JL, Chiang MF, Hsu PH, Tsai DY, Hung KH, Wang YH, Angata T, Lin Kl. OGlcNAcylation is required for $B$ cell homeostasis and antibody responses. Nat Commun. 2017:8(1):1854.

100. Mishra S, Ande SR, Nyomba BL. The role of prohibitin in cell signaling. FEBS J. 2010;277(19):3937-46.

101. Ande SR, Xu YXZ, Mishra S. Prohibitin: a potential therapeutic target in tyrosine kinase signaling. Signal Transduct Target Ther. 2017;2:17059.

102. Lee JH, Nguyen KH, Mishra S, Nyomba BL. Prohibitin is expressed in pancreatic beta-cells and protects against oxidative and proapoptotic effects of ethanol. FEBS J. 2010;277(2):488-500.

103. Farlora R, Nuñez-Acuña G, Gallardo-Escárate C. Prohibitin-2 gene reveals sex-related differences in the salmon louse Caligus rogercresseyi. Gene. 2015;564(1):73-80.

104. Signorile A, Sgaramella G, Bellomo F, De Rasmo D. Prohibitins: a critical role in mitochondrial functions and implication in diseases. Cells. 2019;8(1):71.

Ready to submit your research? Choose BMC and benefit from:

- fast, convenient online submission

- thorough peer review by experienced researchers in your field

- rapid publication on acceptance

- support for research data, including large and complex data types

- gold Open Access which fosters wider collaboration and increased citations

- maximum visibility for your research: over $100 \mathrm{M}$ website views per year

At BMC, research is always in progress.

Learn more biomedcentral.com/submissions 